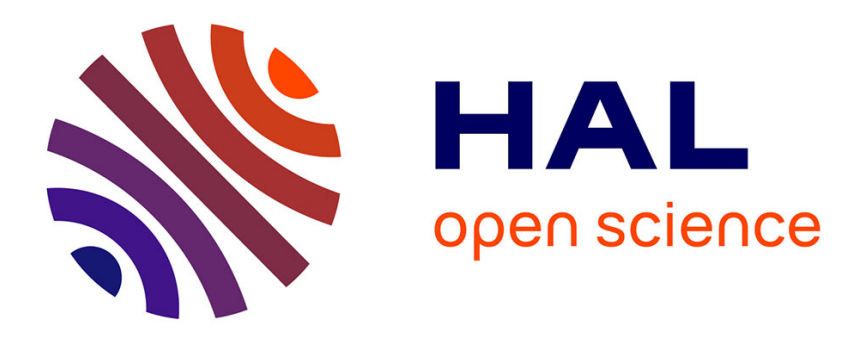

\title{
Managing Heterogeneous Information in a System of Information Systems
}

\author{
Majd Saleh, Véronique Misséri, Marie-Hélène Abel
}

\section{To cite this version:}

Majd Saleh, Véronique Misséri, Marie-Hélène Abel. Managing Heterogeneous Information in a System of Information Systems. 8th International Conference on Knowledge Management and Information Sharing (KMIS 2016), Nov 2016, Porto, Portugal. pp.165-172. hal-01396554

\section{HAL Id: hal-01396554 https://hal.science/hal-01396554}

Submitted on 14 Nov 2016

HAL is a multi-disciplinary open access archive for the deposit and dissemination of scientific research documents, whether they are published or not. The documents may come from teaching and research institutions in France or abroad, or from public or private research centers.
L'archive ouverte pluridisciplinaire HAL, est destinée au dépôt et à la diffusion de documents scientifiques de niveau recherche, publiés ou non, émanant des établissements d'enseignement et de recherche français ou étrangers, des laboratoires publics ou privés. 


\title{
Managing Heterogeneous Information in a System of Information Systems
}

\author{
Majd Saleh $^{1}$, Véronique Misséri ${ }^{2}$ and Marie-Hélène Abel ${ }^{1}$ \\ ${ }^{1}$ Sorbonne Universités, Université de Technologie de Compiègne, CNRS, UMR 7253 Heudiasyc, Compiègne, France \\ ${ }^{2}$ Sorbonne Universités, Université de Technologie de Compiègne, EA 2223 Costech, Compiègne, France \\ $\{$ majd.saleh, veronique.misseri, marie-helene.abel $\} @ u t c . f r$
}

Keywords: Information Systems, Knowledge Management, System of Systems, System of Information Systems

Abstract: Organizations look for information coming from many heterogeneous resources, which are in turn produced by several users working on different Information Systems. Those heterogeneous resources might complement each other, hence producing useful information for the organization. Another possibility is that they might overlap or contradict, therefore producing redundant contradictory information. A common problem that faces organizations here is in the overwhelming amount of the heterogeneous resources produced, and the time required to access and manages those resources under the goal of finding useful information in them. Therefore, one of the most important aspects concerning Information Systems in organizations is the way to manage the knowledge produced from those systems. This issue becomes more significant when dealing with complex Information Systems that work in the digital environment forming the Digital Ecosystem (DE) of modern organizations. As organizations attempts to move forward in this complex Digital Ecosystem, They need to apply out-of-the-box ideas to complex systems such as System of Information Systems (SoIS). Thus, we aim to develop a solution for managing heterogeneous information in a System of Information Systems, and move forward from Digital Ecosystems to Collaborative System of Information Systems. In this paper we present our definition of a Digital Ecosystem. Also, we will detail the model of the SoIS. This model is used to construct the prototype for managing heterogeneous information in a System of Information Systems.

\section{INTRODUCTION}

An organization is a social network of agents that is structured and managed to meet a need or to pursue collective goals (Olson et al., 2005). In recent years the competitive level of organizational work environment is increasing, as changes are taking place much faster than before. One of these changes is the overwhelming amount of resources produced by users working with several Information Systems. These systems are employed in the work environment of organizations. Therefore, the ability to find and classify information distributed in different resources within different Information Systems is of great importance. In turn, this makes innovation, flexibility, coordination, integration, and speed the new success factors of todays work environment. Those factors can be reached through the concept of System of Information Systems (SoIS). This raises the concerns about the development process of SoIS. We need to consider the obstacles and concerns of the collaborative SoIS up front. The collaborative SoIS needs to connect to
Information Systems that cross organizational boundaries, come from multiple disciplines, and generates an overwhelming amount of resources (Majd et al., 2015). In the first place, Users face hard time dealing with the information coming from each Information System independently and keeping track of the generated information. A solution might be found in a well-established collaborative System of Information Systems that provides guidance to manage various types of resources coming from different origins. The collaborative SoIS operates as a single entry point for several Information Systems granting the user access to information produced from multiple Information Systems, and providing the ability to collaborate over available resources to even create an added value not possible to maintain when those systems were operating separately. Furthermore, this solution could be made possible by introducing a knowledge base to the orchestration of the collaborative SoIS. This knowledge base can take the role for storing, organizing, and sharing resources from different Information Systems. Thus, provide the link between resources 
present in different systems and facilitate the communication among them

This paper is organized as follows: section 2 presents the context of this research alongside the state of the art and the problem statement. In section 3 , the objective and model of the collaborative SoIS are presented. Then, the prototype of the collaborative SoIS is presented in section4. After that, in section 5, a discussion of the role of knowledge base in the collaborative SoIS is presented. Finally, this paper is concluded in section 6 .

\section{RESEARCH CONTEXT}

\subsection{Social Context}

There is a growing need not only to use Information Systems, but also to integrate them with other systems that can benefit from the information generated and shared within them. Furthermore, resources provided by different systems can have positive impact on the use of Information Systems.

The following scenario will help in understanding the social context of the work in this paper. For example, a group of researchers are investigating a certain topic of interest. First they might go through various publications to establish the bases for their research and start forming the state-of-art. Next, they might need to unveil the ambiguity on certain aspects to better understand the topic, so one of them starts using scientific databases to search for keywords related to this topic, while the others use the archive system from other databases to search for information. Also, they might use a digital platform in order to facilitate expert group brainstorming sessions. Later on, they might need to share some of their findings to take peer review on them. Of course, not to forget that they need to store and keep track of the information they collected from different Information Systems, the activities of each one of them to assign credit of information, and be able to access the information at all times to reform an encompassing idea about the topic at hand and the progress that has been made.

To sum up, we went over a scenario where several users used several Information Systems and gathered resources from those systems separately. Each user also had to work with the resources collected from separate systems collectively. The struggle is with accessing all these different Information Systems and keeping track of the resources obtained and created while doing the work required. The problems that are highlighted here reside in the time re- quired to traverse between different systems and keep track, organize, and archive all the information obtained from these systems. It is clear from this scenario that users of different Information Systems play key role in creating and diffusing resources in the organization. In order to be able to develop a solution for the problem of knowledge management in organizations, it is important to take into consideration the heterogeneous nature of information distributed over different resources with Information Systems. This view of heterogeneous information in organizations, considering information to be spread across different resources of different origins, and are themselves container for knowledge, will have great impact on the way to manage knowledge in organizations. To achieve the solution we seek to manage knowledge extracted from resources spread over the Information Systems in the Digital Ecosystem of an organization, this study moves towards a System of Information Systems (SoIS) operating with a knowledge base to manage resources coming from different systems and control the process of communication and sharing of heterogeneous information with simplicity and ease. It also focuses on the role of knowledge bases in managing heterogeneous information found in such complex systems.

\subsection{State of Art}

Taking into account the heterogeneous resources, which are shared by collaborators on different Information Systems, could improve the understanding of their field of expertise (Deparis et al., 2014). According to (Deparis et al., 2014) the solution to the problem of experts' identification or research within heterogeneous information of an organization can be reached through the concept of Knowledge Ecosystem (KE). This concept comes directly from Digital Ecosystem (DE) (Bray, 2007). This theory is based on the idea that innovation and learning new skills will be drastically improved in an environment, which favors primarily human interaction and especially the self-learning in a self-organized structure.

The term ecosystem was widespread in the managerial discourse to describe complex environments registered heterogeneous actors collaborating on innovative projects. In the literature, the term appears in the biology introduced by (Tansley, 1935) and expresses a balance between different biological species that interact and compete for survival (biota) in an inorganic environment which is common (biotope). The term was transferred in the domain of the strategy to provide a better understanding of grouping trades around a central object (Gueguen and 
Passebois-Ducros, 2011). The concept was used to illustrate an economic model, the business ecosystems introduced by (Moore, 1996) and (Moore, 2006). The metaphor illustrates professional or sectoral networks and communities gathered around resources, technologies, platforms involving a leading firm (or central firm), the ecosystem is producing an added value for participants. The used of the term of communities (Wenger, 1999), networks or platforms to describe the ecosystem were discussed to progress in the understanding of the concept (Cohendet et al., 2010), (Gueguen and Passebois-Ducros, 2011) and (Iansiti and Levien, 2004). Other versions were introduced as the regional ecosystem introducing a local geographical and spatial dimension. The ecosystem concept is often associated with the practice of open innovation (OI) introduced in 2003 by Henry Chesbrough (Chesbrough, 2003). Digital business Ecosystems or DBE (Dini et al., 2005) try to define the concept applied to a virtual space constituted by heterogeneous numerical devices. In these versions ecosystems include an environment in which stakeholders from multiple organizations will be encouraged to collaborate on various projects including a creative or innovative dimension.

Innovation and participation of different actors in the creation process of added value are common to all these forms of organization. All actors have their own processes, their own systems and platforms. They can cumulate several platforms and tools depending on the projects and communities that they belong to. Some actors have a key role in the ecosystems as a brokers (Granovetter, 1983).

\subsection{Problem Statement}

As established in the context of this research, users have to work with heterogeneous information collected from separate systems collectively. The struggle is with accessing all these different Information Systems. The problems reside in the time required to traverse between different systems and keep track, organize, and archive all the information obtained from these systems. There is a need for a solution that allows us to preserve the autonomous nature of different Information Systems operating within the organization, and still be able to archive, access, track and analyze the resources produced from those systems with the help of a knowledge base. The aim is to move towards a System of Information Systems (SoIS) to manage heterogeneous information coming from different Information Systems and control the process of sharing information with simplicity and ease.

\section{COLLABORATIVE SYSTEM OF INFORMATION SYSTEMS}

\subsection{Objectives}

In the research context we established the problem we face in our work and daily life as the effort required to manage heterogeneous information scattered among Information Systems operating in the Digital Ecosystem of an organization, and keep track, organize, and archive all the information obtained from these systems. Furthermore, managing knowledge in the form of users' activities over resources is of great importance also. To achieve this goal and solve this problem we model and develop a System of Information Systems.

We can summaries the features of the collaborative SoIS based on the work and definition provided by (Carlsson and Stankiewicz, 1991) and (Breschi and Malerba, 1996), and our research context as follows:

- Collaborative SoIS focuses on the role of interrelationships between different Information Systems.

- Collaborative SoIS addresses the flow of information and knowledge found in distributed resources among different Information Systems.

- Collaborative SoIS takes responsibility of generating resources from the emergent Information Systems.

- Resources interoperability is a key issue when designing and developing a collaborative SoIS.

In addition, the collaborative SoIS has the following objectives:

- Provide access to resources coming from different users and Information Systems.

- Create resources in their respected system. These resources can be accessed either from the collaborative SoIS or the dedicated system where they are created.

- Organize these resources in the collaborative SoIS.

- Share resources among different users.

- Annotate resources in order to highlight certain ideas related to the resources.

- Record the users activities from the collaborative SoIS.

To reach the objectives stated before, the collaborative SoIS needs a leader system that plays a leading role in the orchestration of SoIS. This leader system can be a knowledge base serving all other Information 


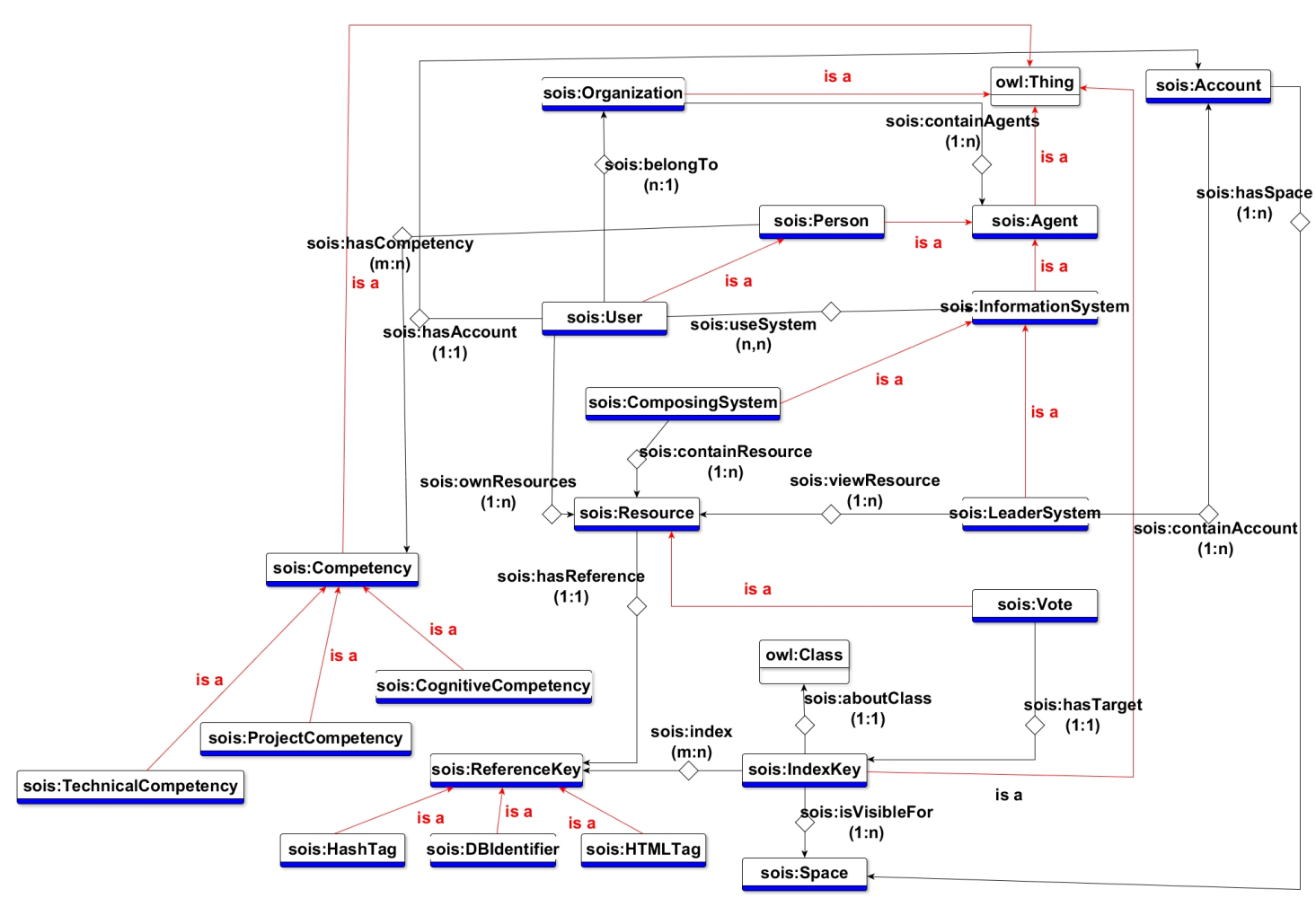

Figure 1: Semantic model of the collaborative SoIS.

Systems. We propose MEMORAe system to play the role of the leader system in the collaborative SoIS.

In (Deparis et al., 2014), the Knowledge Ecosystem is achieved through an Information System called MEMORAe. In order to be clear when presenting MEMORAe it is essential to declare that the idea started as the MEMORAe approach for knowledge management then the approach has led to the development of MEMORAe model and then MEMORAe platform. The MEMORAe approach is based on an original proposal for Knowledge management and moves towards modeling a knowledge Ecosystem, which takes into account the social dimension of organizations. So, what is MEMORAe? As defined by (Ala Atrash, 2014), MEMORAe approach is to manage heterogeneous information resources within organizations. The approach is comprised of a semantic model (called MEMORAe-core 2) and a web platform (called MEMORAe) which is based on the semantic model. The model and the platform make together a support to enhance the process of organizational learning.

The MEMORAe project employs the Semantic Web standards. Based on those standards the ontologies used in the system all come in OWL format. All the users of MEMORAe system are given access to several knowledge bases. When a knowledge base is selected, a user can view a semantic map of concepts related to the chosen base. Then, a user can create and share resources around the concepts of the map. The main contribution of this approach is to allow the indexing of all types of resources around a semantic map of shared terminology in the organization environment. However, this solution is tied down to integrate different types of resources like wikis, forums, or shared calendars inside MEMORAe.

The user of MEMORAe web platform is able to create various resources within the platform. These resources include documents, notes, clusters of notes, weblinks, contacts, events, tours, and forums. The user is also able to index these resources using the semantic map visualized as concepts and instances in MEMORAe. Furthermore, MEMORAe gives users the ability to annotate these resources and share them within different sharing spaces, in addition to tracing users' activities within the platform. While the platform permits creating and managing various types of resources, all of them are native to the platform. Users might benefit more if the capabilities provided by MEMORAe approach (indexing, annotating, sharing, tracing the resources) is applicable to resources created by other Information Systems in the work scope of the user but outside the scope of MEMORAe. Such resources might be emails, wiki pages, 


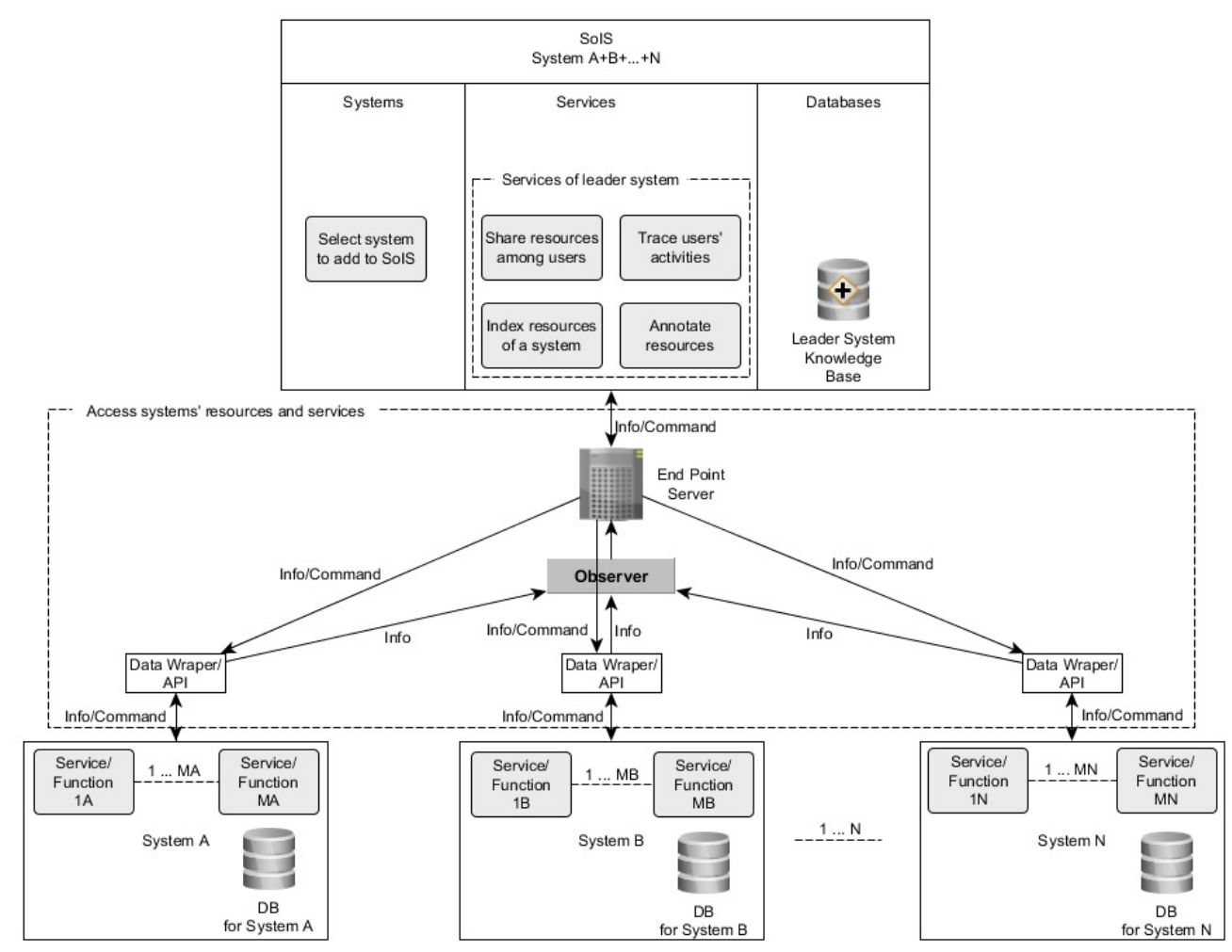

Figure 2: Architectural model of the collaborative SoIS.

social media entries, and other Web 2.0 technologies and services/applications related to users' work. Hence, this paper presents a prototype of the collaborative SoIS that puts MEMORAe approach as a leader system among other Information Systems in the Digital Ecosystem of an organization. That means taking MEMORAe web platform and evolving it into a collaborative SoIS.

\subsection{Model and Architecture}

In the light of the objectives stated earlier, this study presents a semantic model of the collaborative SoIS built using owl (Web Ontology Language) and based on semantic web standards. The model is present in (Fig. 1). The model highlights the position of an agent, either as an Information System or as a user, in the orchestration of the SoIS. The model also shows how resources are created by users and contained in the composing systems of the collaborative SoIS, while the leader system is only showing those resources through a reference key. Each resource has a reference which functions as a link between the resource and the leader system. This key can be an HTML tag, a Database Identifier, or social bookmark as a Hash tag. Following the MEMORAe approach, the leader can view a semantic map of shared terminology in the work environment. The semantic map allows the indexing of references to the actual resources through the index key and sharing it within different sharing spaces.

The architecture of the collaborative SoIS is shown in (Fig. 2). As seen in (Fig. 2), the collaborative SoIS will aggregate heterogeneous information and resources from different Information Systems (System A, System B etc.). These systems are autonomous and work separately of each other. Each of which has its own services/functions and databases. The services/functions of these systems are denoted inside the system (Service/Function 1A, Service/Function 1B etc.). The architectural model here differentiates between services and functions. While some systems are openly providing an API for requesting their services, other systems are closed and operate as black boxes to the outer world and only provide functions invoked within the system itself. Hence the need for data wrappers. The collaborative SoIS is represented as a group of systems connectors, services and databases. The resources does not reside in the collaborative SoIS, but rather can be referenced from the Information Systems comprising it. 


\section{FIRST PROTOTYPE OF THE COLLABORATIVE SoIS}

In this section we propose a prototype developed based on the architectural model presented earlier. Other than the leader system, which is MEMORAe system as discussed earlier, the prototype links to two separate Information Systems. These systems are TiddlyWiki and a brainstorming digital platform.

\subsection{TiddlyWiki}

Technically, a TiddlyWiki is purely an HTML document with a rather large JavaScript section that takes care of displaying all of its contents. The javascript is also responsible for providing the interactive tools for content manipulation. The actual content of the document is not always visible for the user. It is stored in a set of invisible DIV elements, called tiddlers. The content of the DIV elements forms wiki text, i.e. text with a simple markup language. When the user clicks on a tiddler name to show its content, the JavaScript renders and translates the wiki text into HTML to view it for the user. Special fragments can be included in the text to trigger the actions of sub procedures. In addition, some tiddlers are interpreted as a stylesheet or a JavaScript plugin. To edit a tiddler, it is replaced inline by a form, and the user is presented with the original text ready to be edited and saved again (Bagnoli et al., 2006).

\subsection{ECOPACK Brainstorming Platform}

The brainstorming digital platform is developed on the premises of a Digital Ecosystem capable of meeting the needs of innovation and strategic analysis of experts groups. The approach of this digital platform follows the knowledge ecosystem vision that promotes the dynamic evolution of knowledge interactions between users in order to improve decision making and innovation. The technical objectives of the ECOPACK brainstorming platform are as follows:

- Define a multi-user computer platform incorporating several types of devices (tablets, smartphones, PCs) for different forms of collaboration.

- Define collaborative applications accessed from different devices. Each user will benefit from different types of interaction and activity and will be able to exploit his/her own resources to collaborate.

ECOPACK brainstorming platform is a set of heterogeneous data grouped as items, presented and gathered by a main module. The main module is responsible for providing a dynamic representation of the data that allows the interpretation by experts. Work is divided into work sessions. Participants to work sessions are permitted to send comments on he displayed data by the additional modules.

\subsection{The Prototype}

The community members participating in a brainstorming session may have several platforms with dedicated purposes to work with like social networks or wiki systems. Therefore, they might lack a comprehensive view of all resources produced, exchanged and shared within those dedicated systems. For a given subject, they are forced to query each platform to extract the relevant resources. The solution provided by the collaborative SoIS prototype serves as a Digital Ecosystem with a shared repository of a knowledge base.

All the users of the collaborative SoIS are able to access their heterogeneous resources, mostly wiki pages entries and brainstorming projects, from the collaborative SoIS as seen in (Fig. 3). In this figure we can see two boxes used to access TiddlyWiki System an ECOPACK brainstorming platform. Moreover, there is a button with a "plus" sign. This button will allow the user to navigate through all the resources available in the dedicated Information System and select from the list of resources which are going to be indexed by the semantic map and shared in certain sharing spaces. It also allows the user to create new resources in their respected Information System. The resources of the dedicated Information System is made available to the user by means of the data wrapper and the server/observer endpoint shown in the architecture in (Fig. 2).

\section{DISCUSSION}

\subsection{The Role of an Agent in a Collaborative SoIS}

This section elaborates on the agent's role in the collaborative SoIS and how MEMORAe System enables users to manage the resources they created in different Information Systems. It also highlights the importance of the features of MEMORAe system in providing the added value for the collaborative SoIS under study.

In the first prototype of the SoIS presented earlier, MEMORAe system can be viewed as a knowledge base that handles storing, organizing, and sharing of 


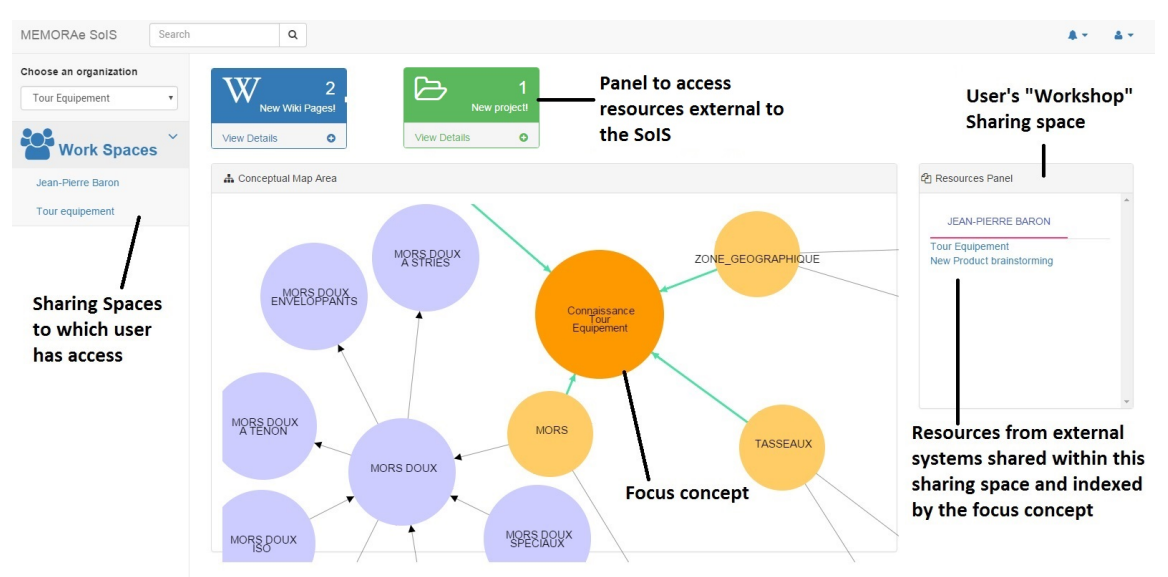

Figure 3: Collaborative SoIS with TiddlyWiki and ECOPACK brainstorming platform.

resources created be users in different Information Systems. MEMORAe system aims, by its original design, to facilitate knowledge sharing and capitalization among different users. All types of resources are indexed by a semantic map that represents the concepts of interest for the users (Atrash et al., 2015). Furthermore, the semantic map defines a common terminology shared between all users and can be used to reference resources targeting the same objective as the indexing concept. The focus concept of the semantic map is a concept in which the user is interested in. The shared resources are indexed by the concepts of the semantic map. In this orchestration of SoIS, MEMORAe is introduced to new resources created by users in different Information Systems that reside outside its scope, hence the use of MEMORAe as it supports different types of social resources (wiki, forums, chat) and documentary resources (documents, images, web link). This constitutes an added value for the Information Systems comprising the SoIS, as resources produced from those systems is capitalized as knowledge within MEMORAe.

User activity traces and recommendation system is another feature of MEMORAe that emphasize on the role of a knowledge base within a SoIS. MEMORAe system owns a mechanism that models, records, and analyzes users traces. It allows evaluating competencies for recommending users with more expertise on certain subjects for either personal purpose or to an entire group of users (Wang et al., 2015).

\subsection{System of Information Systems versus Web Mashup}

A mashup is an application (mostly web application) that combines data, either through APIs or other sources, into a single integrated user experi- ence (Zang et al., 2008). For example, one could combine roads traffic data with a map by integrating geographically-index traffic data with Google Maps interface. Mashup is still a poorly defined and still misunderstood term, and we can say the same about SoIS. There are clear similarities and differences between SoIS and mashup applications.

The main difference between mashups and SoIS is in the direction of communication taking place between different systems or data sources. While SoIS allows, as seen in the presented architecture, communication in both direction between its composite systems, the mashup directs communication flow in on way from data sources to end-user interface (Beemer and Gregg, 2009).

Resources planed to be included in a mashup may be local to the machine on which the mashup is being created or may be remote. Each of these cases requires significant mashup maker design decisions to be made. Selecting the locations of resource to be integrated is an important dimension since it reflects on the infrastructure required both at the server and the client (Galway, 2010).

\section{CONCLUSION}

The goal of this paper was to manage heterogeneous information in a System of Information Systems obtained from different users working with several Information Systems in the digital environment of organizations with simplicity and ease. The aim was focused towards investigating the knowledge base role in facilitating resources management in a Collaborative System of Information Systems (SoIS), and providing a semantic model of SoIS to guide the migration for such complex system. To achieve this 
goal this paper undertakes an effort to present the social and scientific context of this research and define the state of the art, then move to present the semantic model of a collaborative SoIS composed of various Information Systems with MEMORAe approach in its core as a system to manage the resources produced by different systems comprising the collaborative SoIS. This paper found potentials in deploying MEMORAe approach to manage the resources produced by different systems in the collaborative SoIS. It was also clear that combining resources from various Information Systems and manage them within a knowledge base will result in an added value to users not present when those systems were operating separately. The most important value for the collaborative SoIS is in its ability to trace users' activities. Furthermore, the collaborative SoIS can upgrade this value by providing analysis of these activities to determine users' competence levels at certain subjects or importance level of concepts.

The next step is to expand our work and introduce new Information Systems to the SoIS based on the first prototype presented in this study and users' needs. The collaborative SoIS should keep simple interface, with all the resources as far from the user as a single click, to keep the users experience useful and friendly.

\section{Acknowledgement}

This project is done under ECOPACK project and funded by ANR-ASTRID programme.

\section{REFERENCES}

Ala Atrash, Marie-Hélène Abel, C. M. (2014). Supporting organizational learning with collaborative annotation. In 6th international conference on knowledge management and information sharing (KMIS), pages 237- 244 .

Atrash, A., Abel, M.-H., Moulin, C., Darène, N., Huet, F., and Bruaux, S. (2015). Note-taking as a main feature in a social networking platform for small and medium sized enterprises. Computers in Human Behavior.

Bagnoli, F., Jipsen, P., and Sterbini, A. (2006). Tiddlywiki in science education.

Beemer, B. and Gregg, D. (2009). Mashups: a literature review and classification framework. Future Internet, 1(1):59-87.

Bray, D. (2007). Knowledge ecosystems. In Organizational dynamics of technology-based innovation: Diversifying the research agenda, pages 457-462. Springer.
Breschi, S. and Malerba, F. (1996). Sectoral innovation systems: technological regimes, Schumpeterian dynamics and spatial boundaries. Centro studi sui processi di internazionalizzazione, Università commerciale'Luigi Bocconi'.

Carlsson, B. and Stankiewicz, R. (1991). On the nature, function and composition of technological systems. Journal of evolutionary economics, 1(2):93-118.

Chesbrough, H. (2003). Open innovation: the new imperative for creating and profiting from technology. Harvard Business School, Boston, MA.

Cohendet, P., Roberts, J., and Simon, L. (2010). Créer, implanter et gérer des communautés de pratique. Gestion, 35(4):31-35.

Deparis, E., Abel, M.-H., Lortal, G., and Mattioli, J. (2014). Information management from social and documentary sources in organizations. Computers in Human Behavior, 30:753-759.

Dini, P., Darking, M., Rathbone, N., Vidal, M., Hernandez, P., Ferronato, P., Briscoe, G., and Hendryx, S. (2005). The digital ecosystem research vision: 2010 and beyond. position paper ollowing the cycle of workshops 2005 and the online debate, july 2005, bruxelles.

Galway, D. (2010). Mapping mashup makers to a design space.

Granovetter, M. (1983). The strength of weak ties: A network theory revisited. Wiley publications, Sociological Theory, Vol 1, pp 201-203.

Gueguen, G. and Passebois-Ducros, J. (2011). Les écosystèmes d'affaires: entre communauté et réseau. Management \& Avenir, (6):131-156.

Iansiti, M. and Levien, R. (2004). Strategy as ecology. Harvard business review, 82(3):68-81.

Majd, S., Marie-Hélène, A., and Alok, M. (2015). An architectural model for system of information systems. In On the Move to Meaningful Internet Systems: OTM 2015 Workshops, pages 411-420. Springer.

Moore, J. F. (1996). The death of competition: leadership and strategy in the age of business ecosystems. HarperCollins Publishers.

Moore, J. F. (2006). Business ecosystems and the view from the firm. Antitrust Bull., 51:31.

Olson, E. M., Slater, S. F., and Hult, G. T. M. (2005). The performance implications of fit among business strategy, marketing organization structure, and strategic behavior. Journal of marketing, 69(3):49-65.

Tansley, A. G. (1935). The use and abuse of vegetational concepts and terms. Ecology, 16(3):284-307.

Wang, N., Abel, M.-H., Barthes, J.-P., and Negre, E. (2015). Mining user competency from semantic trace. In Computer Supported Cooperative Work in Design (CSCWD), 2015 IEEE 19th International Conference on, pages 48-53. IEEE.

Wenger, E. (1999). Communities of practice: Learning, meaning, and identity. Cambridge university press.

Zang, N., Rosson, M. B., and Nasser, V. (2008). Mashups: who? what? why? In CHI'08 extended abstracts on Human factors in computing systems, pages $3171-$ 3176. ACM. 